\title{
Uר TELEHEALTH
}

\section{All Health Technology Requires Compassion, Collaboration, and Humanism for Optimal Care}

\section{Richard I. Levin ${ }^{1}$ and Brianne Warner Alcala ${ }^{2}$}

Affiliation: ${ }^{1}$ President and CEO, The Arnold P. Gold Foundation; ${ }^{2}$ Director of Communications, The Arnold P. Gold Foundation

Corresponding Author: Brianne Warner Alcala, balcala@gold-foundation.org

Keywords: Telemedicine, Communication, Humanism, Physician's Role, Remote Consultation, PatientCentered Care

Section: Perspective, opinion, and interview

Imagine an appointment with a new patient. She's waiting, fidgeting, looking down at her lap. You say hello, introduce yourself, and sit behind the computer. You enter key details into the EHR (electronic health record) as the appointment goes along. "Tell me why you're here today," you say. You try listening, but menus keep popping up. The patient launches into her complaints, knowing that time is limited. You type as fast as you can to keep up.

Soon, it has been 10 minutes, and you need to wrap things up and move on to the next patient. Did you feel connected to the patient? Did she feel connected to you? Perhaps neither of you made eye contact. Both of you might have left the appointment feeling unsatisfied and unsettled.

To feel connected to a patient requires more than being in the same room. In fact, being in the same room may not be essential. Connecting with a patient or another healthcare team member requires humanism - the simple act of being human - and the deliberate acts that accompany it. For those working in telehealth, creating a bond with a patient can be a bit different but no less important or possible than in a physical room.

\section{BEST PRACTICES FOR ELECTRONIC HEALTH RECORDS}

Dr. Wei Wei Lee and Dr. Lolita Alkureishi of the University of Chicago have studied the modern "computer side" manner and best practices around the use of the electronic health record. Regardless of whether a physician is in the room with a patient, the information available by computer can be distracting. They advise physicians to do their homework before meeting a patient: review the patient chart and prepare items to discuss. 
Their research, in part funded by The Arnold P. Gold Foundation, ${ }^{1}$ backs up the use of what they call the "Golden Minute" - a sacred time at the start of the appointment that focuses on the patient. The keyboard is set aside, as the physician and patient engage in conversation.

When a true connection is made between a patient and a healthcare professional, trust increases. Studies reveal that health outcomes and even the rate of malpractice suits are closely related to physicians' interpersonal skills and the quality of the patient-physician relationship. ${ }^{2,3}$ The human connection is not fluff or a bonus nicety, but a core component of the best healthcare.

Compassion and empathy allow healthcare professionals - nurses, physicians, and the whole team - to reach a better understanding of their patients and their needs. This bond helps patients and the healthcare team collaborate to reach optimal health outcomes.

\section{ARNOLD P. GOLD FOUNDATION}

The Gold Foundation ${ }^{1}$ began 30 years ago precisely because a singular physician feared the human connection was becoming lost in medicine. A pediatric neurologist, the late Dr. Arnold Gold knew the great benefits of listening intently and asking about the family. Knowing the patient is much more than a diagnosis. He co-founded the nonprofit organization with his wife, Sandra Gold, in order to explicitly make humanism a core element of healthcare education and practice.

The Gold Foundation defines humanism through the "I.E., C.A.R.E.S." mnemonic: Integrity, Excellence, Collaboration \& Compassion, Altruism, Respect \& Resilience, Empathy, and Service. None of these components require that a patient and a healthcare professional be in the same room, but all require thoughtfulness and attention.

\section{EXPLORING OPTIONS}

As telehealth services increase, healthcare providers are finding ways to connect with patients. Dr. Joshua Ackerman is a psychiatrist with Innovatel, based out of Erie, Pennsylvania. He lives in New Jersey and works with patients in St. Cloud, Minnesota.

"Over time, I developed a style of talking to the patient that didn't draw attention to the separation - but rather, incorporated it," he explains. "I'll often mention I'm in New Jersey. A lot of the patients may think I'm a mile away or so in Minnesota. That's a way to bridge that gap. I'm a person, not an automaton from the waist up."4

Eye contact is another a key component to building a connection - essential both in person and in telehealth. "I'm much more in tune to eye contact and body language now because of some of the other senses I'm not engaging," explains Dr. Ackerman."

Sometimes, trial and error are necessary to figure out how best to foster the human connection across the digital screens. Dr. Ackerman learned from a colleague that while he was talking to her, through the telemedicine screen, it seemed as though he was looking down rather than at her. We all have had this experience with digital media.

"The camera is just on the rim of the screen. If I stand too close, patients see that my eyes have a downward gaze. So, I maintain about a two-foot distance from the camera." He is now aware of the right distance to maintain eye contact with his patients.

All of these tips, and others that you may discover and implement in your own practice, 
are a critical part of the best healthcare. Rather than substitute a physical presence for a sense of connection, telemedicine demands the conscious decision to engage fully.

"The dynamic of telemedicine requires me to establish and maintain a unique humanistic approach that helps minimize the geographic separation," says Dr. Ackerman. "That's been extremely enjoyable for me to be able to do that."

\section{FINAL THOUGHTS}

Physicians, nurses, and the entire healthcare team must take full advantage of this opportunity in telemedicine to connect with patients, see them as full human beings, and share their own humanity.

More about Dr. Lolita Alkureishi and Dr. Wei Wei Lee's research is available on the Gold Foundation website, ${ }^{5}$ with links to a downloadable kit, instructive comics, and more patient-centered EHR tools.

\section{Funding Statement: N/A}

\section{Conflict of Interest: N/A}

Contributors: To fulfil all of the criteria for authorship, every author of the manuscript has made substantial contributions to ALL of the work and participated sufficiently in the work to take public responsibility.
Copyright Ownership: The Arnold Gold Foundation

\section{REFERENCES}

1. The Arnold P. Gold Foundation. 2018. URL: http://www.gold-foundation.org/

2. Rakel D, Barrett B, Zhang Z, et al. Perception of empathy in the therapeutic encounter: effects on the common cold.

J. Patient Educ Couns. 2011

Dec;85(3):390-7. URL:

https://www.ncbi.nlm.nih.gov/pubmed/2 1300514

3. Hannawa AF, Shigemoto Y, Little TD. Medical errors: Disclosure styles, interpersonal forgiveness, and outcomes. Soc Sci Med. 2016 May;156:29-38.

URL:

https://www.ncbi.nlm.nih.gov/pubmed/2 7017088

4. Phone interview with Dr. Joshua Ackerman by Brianne Alcala, February 2018.

5. Alkureishi L, Lee WW. Tuning foe into friend: Leveraging the electronic record to promote humanism. Gold Foundation. 2018. URL: http://www.goldfoundation.org/newsroom/news/turningfoe-friend-leveraging-electronic-healthrecord-promote-humanism/ 